\title{
Digital radiography as an alternative method in the evaluation of bone density in uremic rats
}

Radiografia digital como método alternativo na avaliação da densidade óssea em ratos urêmicos

\section{Authors}

Bárbara Bruna Abreu de Castro ${ }^{1,2,3}$ iD

Wander Barros Carmo $1,2,3$ iD

Jasmin ${ }^{3}$ iD

Roberto Sotto Maior Fortes Oliveira ${ }^{3}$ iD

Vera Maria Peters ${ }^{3}$ iD

Vanda Jorgetti ${ }^{4}$ iD

Melani Ribeiro Custodio ${ }^{4}$ iD

Helady Sanders-Pinheiro ${ }^{1,2,3}$ iD

${ }^{1}$ Universidade Federal de Juiz de Fora, Laboratório de Nefrologia

Experimental e Núcleo de Experimentação Animal, Juiz de Fora, MG, Brasil.

${ }_{2}$ Universidade Federal de Juiz de Fora, Divisão de Nefrologia e Núcleo Interdisciplinar de Estudos e Pesquisa em Nefrologia, Juiz de Fora, MG, Brasil.

${ }^{3}$ Universidade Federal de Juiz de Fora, Centro de Biologia da Reprodução, Juiz de Fora, MG, Brasil.

${ }^{4}$ Universidade de São Paulo, Faculdade de Medicina, Laboratório de Fisiopatologia Renal, São Paulo, SP, Brasil.

Submitted on: 01/10/2019. Approved on: 04/24/2019.

\section{Correspondence to:}

Helady Sanders-Pinheiro.

E-mail: heladysanders@gmail.com

DOI: 10.1590/2175-8239-JBN-2019-0008

\section{Abstract}

Introduction: Digital radiography (DRx) may provide a suitable alternative to investigate mineral and bone disorder (MBD) and loss of bone density (BD) in rodent models of chronic kidney disease (CKD). The objective of this study was to use DRx to evaluate BD in CKD rats, and to evaluate the correlation between DRx findings and serum MBD markers and bone histomorphometry. Methods: Uremia was induced by feeding Wistar rats an adenine-enriched diet $0.75 \%$ for 4 weeks $/ 0.10 \%$ for 3 weeks); outcomes were compared to a control group at experimental weeks 3,4 , and 7 . The following biochemical markers were measured: creatinine clearance $(\mathrm{CrC})$, phosphate $(\mathrm{P})$, calcium $(\mathrm{Ca})$, fractional excretion of $\mathrm{P}(\mathrm{FeP})$, alkaline phosphatase (ALP), fibroblast growth factor-23 (FGF-23), and parathyroid hormone (PTH). DRx imaging was performed and histomorphometry analysis was conducted using the left femur. Results: As expected, at week 7, uremic rats presented with reduced $\mathrm{CrC}$ and higher levels of P, FeP, and ALP compared to controls. DRx confirmed the lower BD in uremic animals $(0.57 \pm 0.07$ vs. $0.68 \pm 0.06$ a.u.; $p=0.016$ ) compared to controls at the end of week 7 , when MBD was more prominent. A severe form of high-turnover bone disease accompanied these biochemical changes. BD measured on DRx correlated to $\mathrm{P}(\mathrm{r}=-0.81 ; p$ $=0.002), \operatorname{ALP}(r=-0.69, p=0.01)$, PTH $(\mathrm{r}=-0.83, p=0.01), \mathrm{OS} / \mathrm{BS}(\mathrm{r}=-0.70 ; p$ $=0.02)$, and $\mathrm{ObS} / \mathrm{BS}(\mathrm{r}=-0.70 ; p=0.02)$. Conclusion: BD quantified by DRx was associated with the typical complications of MBD in CKD and showed to be viable in the evaluation of bone alterations in CKD.

Keywords: Bone Density; Radiography; Disease Models, Animal; Renal Insufficiency, Chronic; Chronic Kidney DiseaseMineral and Bone Disorder.

\section{Resumo}

Introdução: A radiografia digital $(\mathrm{RxD})$ pode representar uma alternativa adequada para investigar o distúrbio mineral e ósseo (DMO) e a perda de densidade óssea (DO) em modelos de roedores da doença renal crônica (DRC). O objetivo deste estudo foi utilizar a $\mathrm{RxD}$ para avaliar a $\mathrm{DO}$ em ratos com DRC, e avaliar a correlação entre os achados da $\mathrm{RxD}$ e marcadores séricos de DMO e histomorfometria óssea. Métodos: A uremia foi induzida pela alimentação de ratos Wistar com dieta enriquecida com adenina $(0,75 \%$ por 4 semanas $/ 0,10 \%$ por 3 semanas); os resultados foram comparados com um grupo controle nas semanas experimentais 3, 4 e 7 . Os seguintes marcadores bioquímicos foram medidos: clearance de creatinina $(\mathrm{CCr})$, fosfato $(\mathrm{P})$, cálcio $(\mathrm{Ca})$, fração excretada de $\mathrm{P}(\mathrm{FeP})$, fosfatase alcalina (ALP), fator de crescimento de fibroblastos-23 (FGF-23) e paratormônio (PTH). A imagem da $\mathrm{RxD}$ foi obtida e a análise histomorfométrica foi realizada com o fêmur esquerdo. Resultados: como esperado, na semana 7 , os ratos urêmicos apresentaram redução do $\mathrm{CCr}$ e níveis mais altos de $\mathrm{P}$, $\mathrm{FeP}$ e ALP em comparação aos controles. A RxD confirmou a menor $\mathrm{DO}$ em animais urêmicos $(0,57 \pm 0,07$ vs. $0,68 \pm 0,06$ u.a.; $p=0,016$ ) em comparação aos controles no final da semana 7, quando a DMO foi mais proeminente. Uma forma grave de doença óssea de alta renovação celular acompanhou essas mudanças bioquímicas. A DO, medida na $\mathrm{RxD}$ foi correlacionada a $\mathrm{P}(\mathrm{r}=-0,81 ; p=$ $0,002), \operatorname{ALP}(\mathrm{r}=-0,69, p=0,01), \mathrm{PTH}(\mathrm{r}=$ $-0,83, p=0,01)$, OS/BS $(\mathrm{r}=-0,70 p=0,02) \mathrm{e}$ Ob.S/BS ( $r=-0,70 ; p=0,02)$. Conclusão: A DO quantificada por RxD esteve associada às complicações típicas da DMO na DRC e mostrou-se viável na avaliação de alterações ósseas na DRC.

Palavras-chave: Densidade Óssea; Radiografia; Modelos Animais de Doenças; Insuficiência Renal Crônica; Distúrbio Mineral e Ósseo na Doença Renal Crônica. 


\section{INTRODUCTION}

In humans, trabecular bone has a turnover rate approximately 8 times faster than that of compact bone, and it is highly responsive to metabolic stimuli ${ }^{1}$. This high turnover rate makes trabecular bone the primary site for the detection of early bone loss that precedes fractures, and for monitoring the efficacy of different treatments aiming to prevent or slow down bone loss in clinical settings ${ }^{2}$. Thus, the evaluation of bone density $(\mathrm{BD})$ is considered a major clinical tool for the detection of pathologies affecting bone structure ${ }^{3}$.

Bone density is assessed using densitometry methods that are based on the principle of differential absorption of photons by tissues of different radiodensities, as well as by different regions of varying radiodensities within the same tissue. The absorption of photons is directly related to the thickness and composition of the bone tissue. Therefore, as BD decreases, less photons are absorbed, resulting in the attenuation of the radiographic signal ${ }^{4,5}$.

Dual-energy X-ray absorptiometry (DXA) is the most used densitometry method to evaluate bone quantitatively in the general population, as it is non-invasive, uses low doses of radiation, and provides BD with high precision and good sensitivity and specificity. Quantitative computed tomography (QCT) is being increasingly used as an alternative method, sharing the same attributes as DXA but with the added advantage of providing separate assessment of cortical and trabecular $\mathrm{BD}^{4-6}$.

The trabecular bone score is a new method that estimates the trabecular microarchitecture from DXA images. Studies in humans confirm its association with the findings of QCT and with trabecular bone assessment by bone histomorphometry, making this a promising method for the evaluation of fracture risk in individuals with and without renal disease ${ }^{7,8}$. In patients with chronic kidney disease (CKD), histomorphometry is considered the gold standard for the assessment of $\mathrm{BD}^{4,6}$. As histomorphometry is highly invasive, alternative non-invasive methods are being studied, combining imaging techniques with analysis of bone turnover biomarkers in order to assess fracture risk in patients with $\mathrm{CKD}^{5,9}$.

In experimental studies, the digital radiography (DRx) has also been used for the evaluation of $\mathrm{BD}^{10,11}$. With DRx, digital images are obtained electronically, converted to numerical data using a custom software, sampled, and stored for off-line analysis. For analysis, the digital image is divided into pixels, and the grey scale tone for each pixel is numerically coded. Thus, each pixel is associated with a number representing the color of in the area or the intensity of gray tones. In this way, the image is converted into a set of numbers and can be visualized on a computer screen or be printed for analysis ${ }^{12,13}$. To date, DRx has not been used for analysis of mineral and bone disorder (MBD) in experimental models of CKD.

The objective of this study was to evaluate $\mathrm{BD}$ in uremic rats using DRx, and to evaluate the association of image-based measures with the biochemical markers of renal MBD and with aspects of bone histomorphometry.

\section{Methods}

\section{STATEMENT OF ETHICS}

All procedures were performed in accordance with the Brazilian Federal Law, $\left(11,794\right.$, October $8^{\text {th }}$ 2008) and the guidelines of the National Council for the Control of Animal Testing. The study was approved by the Ethics Committee of Animal Use of Federal University of Juiz de Fora, Protocol number 031/2013.

\section{EXPERIMENTAL PROTOCOL AND DIETS}

Male Wistar rats 8 to 12 weeks old, weighing $200 \mathrm{~g}$ to $300 \mathrm{~g}$ were used. The animals were obtained from the Biology Center of the Federal University of Juiz de Fora and randomly divided into two groups (Control and uremic groups,) containing 24 animals each. The animals in the Control group were fed a standard diet (Pragsoluções, Jau, Brazil) until the end-point of 7 weeks. Uremic group animals were fed a $0.75 \%$ adenine enriched-diet for 4 weeks followed by a $0.10 \%$ adenine enriched-diet in the following 3 weeks (Pragsoluções) (Figure 1).

Eight animals from each group were euthanized at experimental weeks 3,4 , and 7 . The day before euthanasia, animals were housed in metabolic cages for a 24$\mathrm{hr}$ urine collection. The animals were anesthetized with xylazine $(10 \mathrm{mg} / \mathrm{kg}$ ) and ketamine $(90 \mathrm{mg} / \mathrm{kg})$ (König, Avellaneda, Argentina), IP. Blood samples were collected by cardiac puncture. Left femurs were removed for DRx analysis and bone histomorphometry. 
Figure 1. From day 0 to day 49 (7 weeks), standard diet was administered to the Control group. From day 0 to day 28 (4 weeks), $0.75 \%$ adenine diet was administered to the Uremic group. At the day 28 , the $0.75 \%$ adenine diet was stopped, and from day 28 to day 49 (i.e., 3 weeks), a $0.1 \%$ adenine diet was administered to the Uremic group. Body weight, food and water intake were measured once a week. Stars indicate the timepoints of measurement of water intake, urine volume, and euthanasia $(\mathrm{N}=8)$.

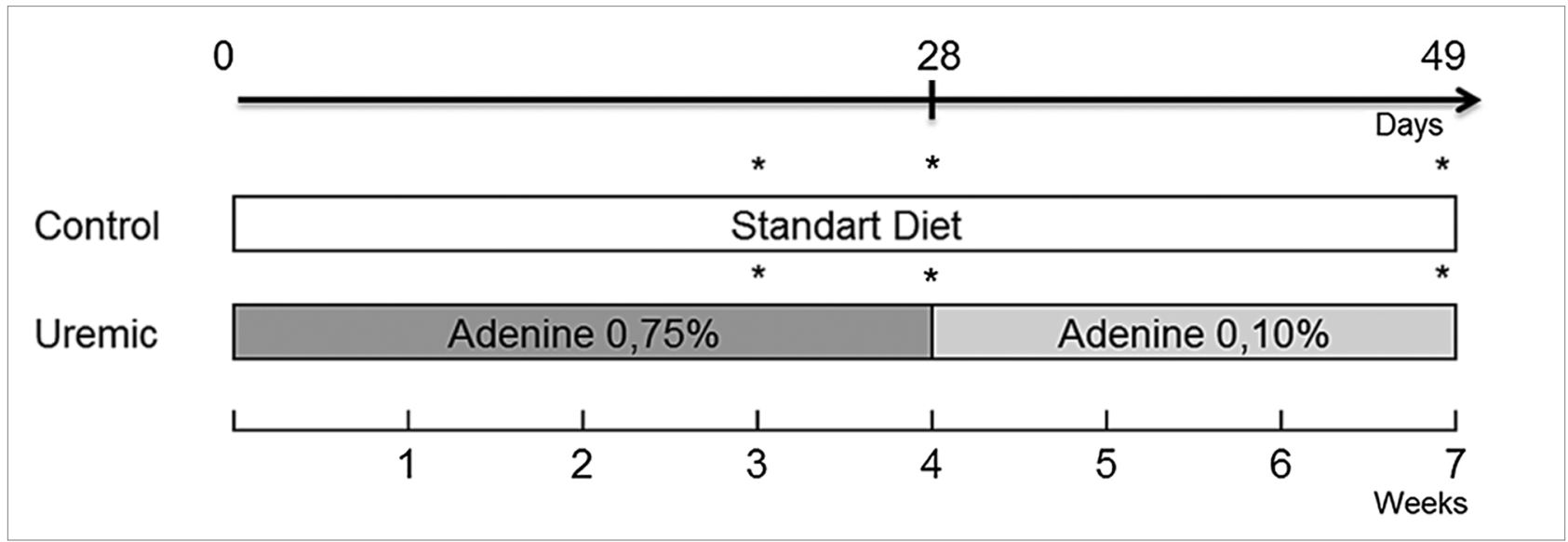

\section{BIOCHEMICAL PARAMETERS}

At weeks 3, 4 and 7, serum creatinine, P, ALP, and $\mathrm{Ca}$, and urinary creatinine and $\mathrm{P}$ levels were determined using an automatic analyzer, LabMax Progress (Labtest Diagnostica SA, Lagoa Santa, Brazil). Additionally, serum parathyroid hormone (PTH) (Rat Intact PTH ELISA kit, Immutopics, San Clemente, USA) and fibroblast growth factor-23 (FGF-23) (FGF23 ELIZA kit, Clone Cloud Corp. Houston, USA) assays were performed by ELISA (R \& D Systems, Minneapolis, USA).

\section{BONE HISTOMORPHOMETRY}

The left femur of 5 animals per group was removed, dissected free of soft tissue, immersed in $70 \%$ ethanol, and processed as described previously ${ }^{14}$. Static, structural, and dynamic parameters of bone formation and resorption were measured in distal metaphysis (magnification 250x; 30 fields), $195 \mu \mathrm{m}$ from the epiphyseal growth plate, using an OsteoMeasure image analyzer (Osteometrics, Atlanta, GA, USA). Structural parameters included trabecular thickness (in $\mu \mathrm{m}$ ), trabecular separation (in $\mu \mathrm{m}$ ), and trabecular number (in trabeculae $/ \mathrm{mm}$ ). The indices of static formation included the proportion of trabecular bone volume and osteoid volume to total bone volume (both in $\%$ ), osteoid thickness (in $\mu \mathrm{m}$ ), and osteoid/osteoblast surfaces (both in \% of bone surface). The indices of static resorption included eroded surface and osteoclast surface (both in \% of bone surface). Mineral apposition rate was determined from the distance between the two tetracycline labels, divided by the time interval between the two tetracycline administrations and expressed in $\mu \mathrm{m} /$ day. Mineralization lag time was expressed in days. The percentage of double tetracycline-labeled (mineralizing) surface per bone surface and bone formation rate completed the dynamic evaluation. Results are also described according to the turnover mineralization volume (TMV) classifica$\operatorname{tion}^{15}$. Histomorphometric indices were reported using the nomenclature recommended by the American Society of Bone and Mineral Research ${ }^{16}$. All animal data were obtained by examiners blinded to the study protocol.

\section{Evaluation of BD by DRx}

For DRx analysis (direct method), the left femur of 6 animals per group was fixed in $100 \%$ ethanol. Images of the whole bone were then captured using a Kodak In vivo Image Station PRO, equipped with a CCD camera (Carestream Health Inc., Rochester, NY). The DRx images were obtained using the following parameters: $60 \mathrm{~s}$ exposure time, $2 \times 2$ binning, KVP35, $0.8 \mathrm{~mm}$ aluminum filter, $2.8 \mathrm{f}$-stop, and $80 \mathrm{~mm}$ field of vision. The acquired images were analyzed using the Carestream MI Application software (version 5.0.2.30, Carestream Health Inc.). After image calibration to optical density, the bone area was delimited using the automatic selection tool and the mean grey intensity for each pixel in the delimited area quantified in arbitrary units (a.u. $)^{11,13,17}$.

\section{StATISTICAL ANALYSIS}

The data are reported as mean \pm standard deviation or median with minimum and maximum, as appropriate for the data distribution evaluated using the 
Kolmogorov-Smirnov test of normality. Comparisons between biochemical parameters of CKD MBD for the Uremic and Control groups were performed using Student's $t$-test. Pearson's and Spearman's correlation coefficients were used to evaluate the relationship between $\mathrm{BD}$, measured by $\mathrm{DRx}$, and biochemical parameters and aspects of bone histomorphometry at week 7. Statistical significance was set at a $p$-value $<0.05$, and all analyses were performed using SPSS statistical software (Version 21; IBM Corporation, Chicago, IL).

\section{Results}

\section{MORTALITY AND BIOCHEMICAL PARAMETERS}

One animal died in the Uremic group at week 3 . The results of the adenine-enriched diet on $\mathrm{CrC}$ are shown in Figure 2A. CrC was markedly decreased in the Uremic group at week 4, following the initial diet with $0.75 \%$ adenine enrichment for 4 weeks, with levels of $0.11 \pm 0.04 \mathrm{~mL} / \mathrm{min} / 100 \mathrm{~g}$ compared to $0.75 \pm 0.44$ $\mathrm{mL} / \mathrm{min} / 100 \mathrm{~g}$ for animals in the Control group $(p=$ 0.016). This renal dysfunction in the Uremic group persisted for 3 weeks after the reduction of dietary adenine concentration to $0.1 \%$, with $\mathrm{CrC}$ levels at week 7 of $0.16 \pm 0.06 \mathrm{~mL} / \mathrm{min} / 100 \mathrm{~g}$ compared to $0.62 \pm 0.29 \mathrm{~mL} / \mathrm{min} / 100 \mathrm{~g}$ for the Control group $(p$ $=0.01$ ).

Renal dysfunction was associated with MBD characterized by specific biochemical abnormalities. Hyperphosphatemia was found in the Uremic animals at the 3 time-points (Figure 2B). P levels in the Uremic group doubled compared to animals in the Control group at week 4 , with levels of $14.70 \pm 4.87 \mathrm{mg} / \mathrm{dL}$ and $7.11 \pm 0.71 \mathrm{mg} / \mathrm{dL}$, respectively $(p=0.01)$. P levels remained high at week 7 , with values of $10.61 \pm$ $2.49 \mathrm{mg} / \mathrm{dL}$ and $6.82 \pm 0.53 \mathrm{mg} / \mathrm{dL}$ for the Uremic and Control groups, respectively ( $p=0.001$ ) (Figure $2 \mathrm{~B}$ ).

ALP was statistically higher in the Uremic group compared to the Control group, at all 3 time-points (Figure 2C). In the Uremic group, ALP gradually increased to $383.14 \pm 109.55 \mathrm{u} / \mathrm{L}$ at week $3,452.71$ $\pm 153.43 \mathrm{u} / \mathrm{L}$ at week 4 , and $561 \pm 90.90 \mathrm{u} / \mathrm{L}$ at the end-point of the experiment (week 7). The fractional excretion of $\mathrm{P}(\mathrm{FeP})$ increased while the renal function worsened. The FeP levels were elevated for animals in the Uremic group compared to the Control group, at the 3 time-points (Figure 2D). FeP levels in Uremic animals increased to $34.21 \pm 8.63 \%$ and $71.59 \pm$ $20.23 \%$ at weeks 3 and 7 , respectively, compared to $20.06 \pm 16.83 \%$ at week 7 for animals in the Control group. While Ca levels were comparable between groups at weeks 3 and 4, levels were elevated for animals in the Uremic group at week 7 (Figure 2E).

An increase in FGF-23 levels was expected to parallel the increase in renal dysfunction. In our animal model, however, levels of FGF-23 presented a tendency for higher value only at week 3 (Figure 2F). While PTH levels were widely variable in the Uremic group, levels were consistently higher compared to the Control group at weeks 3 and 4 (Figure 2G). Comparative values were of $2,659.20 \pm 392.57 \mathrm{pg} /$ dL vs. $214.84 \pm 53.31 \mathrm{pg} / \mathrm{dL}$ ( $p=0.001)$, respectively, for the Uremic and Control groups at week 3, and $3,769.40 \pm 1693.62 \mathrm{pg} / \mathrm{dL}$ vs. $214.84 \pm 53.31 \mathrm{pg} / \mathrm{dL}$ ( $p=0.01$ ), respectively, at week 4 . At week 7 there was only a tendency for PTH levels to be higher in the Uremic group $(5,940.2 \pm 5,740.35 \mathrm{pg} / \mathrm{dL}$ vs. $272.3 \pm$ 192. $22 \mathrm{pg} / \mathrm{dL} ; p=0.09$ ) (Figure $2 \mathrm{G}$ ).

\section{BONE HISTOMORPHOMETRY}

Bone histomorphometry revealed that structural bone parameters did not differ between groups (Table 1). The bone formation rate (BFR/BS) was significantly higher in the CKD group than in the Control group. Other parameters of bone formation, such as osteoid (OS/BS), osteoclast (Oc.S/BS), and osteoblast (Ob.S/ $\mathrm{BS})$ surfaces were also significantly higher in the CKD group (Table 1). These findings confirmed the achievement of a high-turnover bone disease.

\section{Evaluation of BD by DRx}

Comparative qualitative analysis of $\mathrm{BD}$ images of the left femurs of animals from the Uremic and Control groups are shown in Figure 3A e 3B. The left femur of Uremic animals showed several areas of severe bone reabsorption, indicative of bone rarefaction. Areas of diminished cortical bone thickness and expansion of trabecular bone were identified surrounding regions of rarefaction (Figure 3A"). Optical density analysis of the entire femur (Figure 3B) indicated significantly lower BD in the Uremic group, with BD values of $0.57 \pm 0.08$ a.u. compared to $0.73 \pm 0.10$ a.u. for the Control group $(p=0.01)$ at week 4 , and $0.58 \pm 0.07$ a.u. vs $0.68 \pm 0.06$ a.u., respectively, at week 7 ( $p=$ $0.016)$. 
Figure 2. Biochemical parameters collected at weeks 3,4 and 7: (A) Creatinine clearance $(\mathrm{CrC}),(\mathrm{mL} / \mathrm{min} / 100 \mathrm{~g})$, (B) Serum phosphate (P) $(\mathrm{mg} / \mathrm{dL})$, (C) Alkaline phosphatase (ALP) (u/L), (D) Fractional excretion of P (FeP) (\%), (E) Serum Calcium (Ca) (mg/dL), (F) fibroblast growth factor-23 (FGF23) $(\mathrm{pg} / \mathrm{dL})$ and $(\mathrm{G})$ Parathyroid hormone $(\mathrm{PTH})(\mathrm{pg} / \mathrm{dL})$. Data are expressed as mean \pm SD for each group, and Student's $t$-test used to compare data at each week, ${ }^{*} p<0.05$.
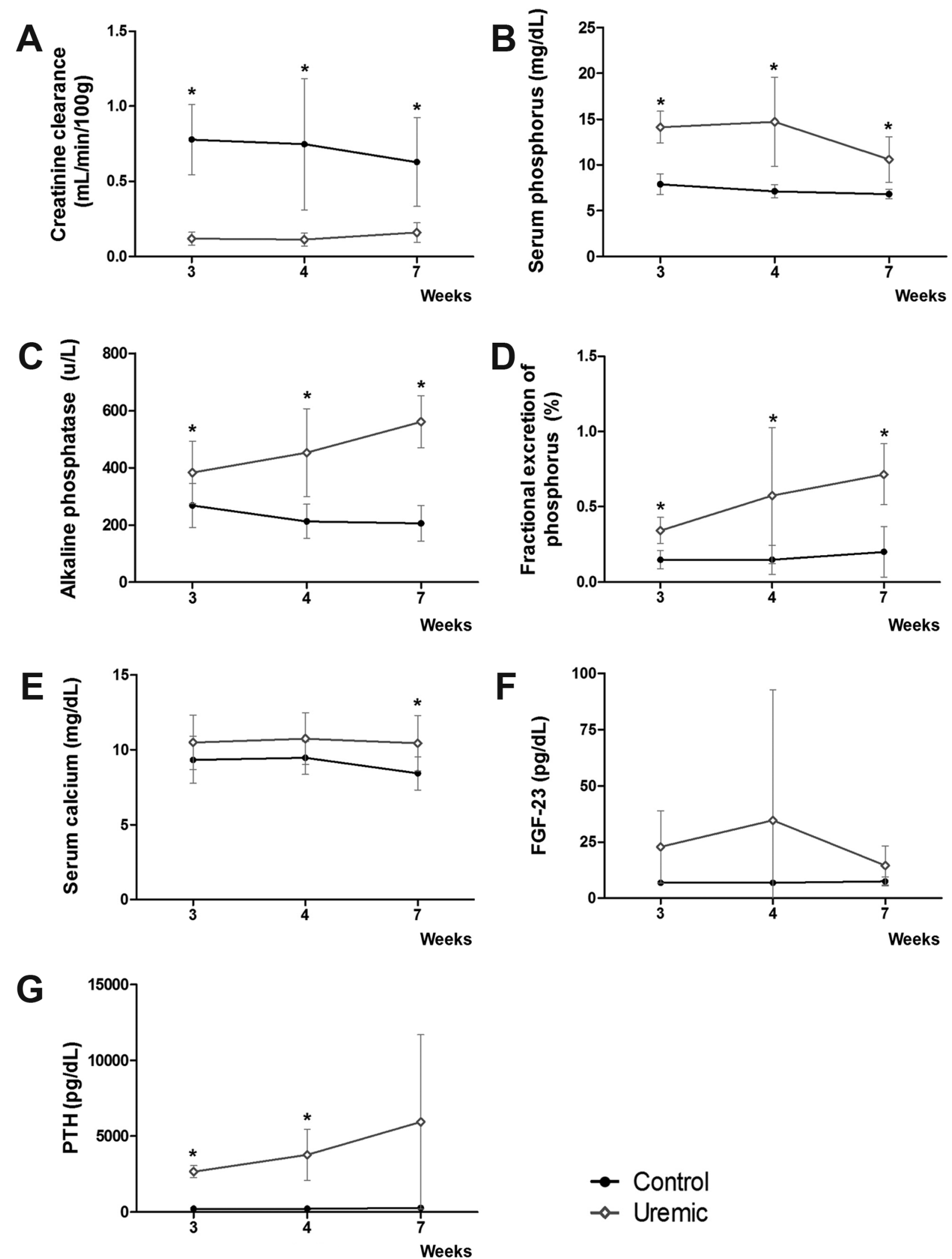
TABLE 1 BONE HISTOMORPHOMETRY DATA AFTER 7 WEEKS

\begin{tabular}{|c|c|c|c|}
\hline Bone parameters & Control & Uremic & $p$ \\
\hline \multicolumn{4}{|l|}{ Structural parameter } \\
\hline Trabecular Volume (BV/TV, \%) & $22.64 \pm 3.71$ & $25.69 \pm 15.83$ & 0.686 \\
\hline Trabecular Number (Tb.N, mm) & $4.20 \pm 0.35$ & $4.46 \pm 2.48$ & 0.810 \\
\hline Trabecular Thickness (Tb.Th, $\mu \mathrm{m})$ & $54.03 \pm 8.57$ & $57.78 \pm 17.92$ & 0.680 \\
\hline Trabecular Separation (Tb.Sp, $\mu \mathrm{m}$ ) & $185.25 \pm 18.63$ & $265.23 \pm 229.92$ & 0.434 \\
\hline \multicolumn{4}{|l|}{ Formation parameter } \\
\hline Osteoid Thickness (O.Th, $\mu \mathrm{m})$ & $0.97(0.49-1.46)$ & $4.99(2.63-25.68)$ & 0.077 \\
\hline Osteoid Surface (OS/BS, \%) & $1.87 \pm 1.13$ & $33.20 \pm 21.33$ & 0.010 \\
\hline Osteoblast Surface (Ob.S/BS, \%) & $1.71 \pm 0.97$ & $22.79 \pm 11.67$ & 0.007 \\
\hline Mineralizing Surface (MS/BS, \%) & $1.58 \pm 0.77$ & $2.59 \pm 0.86$ & 0.139 \\
\hline Mineral Apposition Rate (MAR, $\mu \mathrm{m} /$ day) & $0.37 \pm 0.20$ & $1.32 \pm 0.66$ & 0.021 \\
\hline Bone Formation Rate (BFR/BS, $\mu \mathrm{m}^{3} / \mu \mathrm{m}^{2} /$ day) & $0.01(0.0-0.01)$ & $0.03(0.02-0.04)$ & 0.004 \\
\hline \multicolumn{4}{|l|}{ Resorption parameter } \\
\hline Eroded Surface (ES/BS, \%) & $3.67 \pm 0.91$ & $14.20 \pm 7.42$ & 0.017 \\
\hline Osteoclast Surface (Oc.S/BS, \%) & $1.09(0.32-1.13)$ & $5.32(0.34-7.19)$ & 0.012 \\
\hline
\end{tabular}

Figure 3. (A) Representative Digital Radiography (DRx) of left femurs from each group, presented in colour scale. ( $A^{\prime}$ ) Representative DRx in grey tones for the femur of an animal in the Control group, and $\left(A^{\prime \prime}\right)$ Representative DRx grey tones for the femur of an animal from the Uremic group. (B) Bone density calculated from the mean intensity of grey tones (a.u.). Data are expressed as mean \pm SD in each group and Student's $t$-test used to compare data at each week, ${ }^{*} p<0.05$.

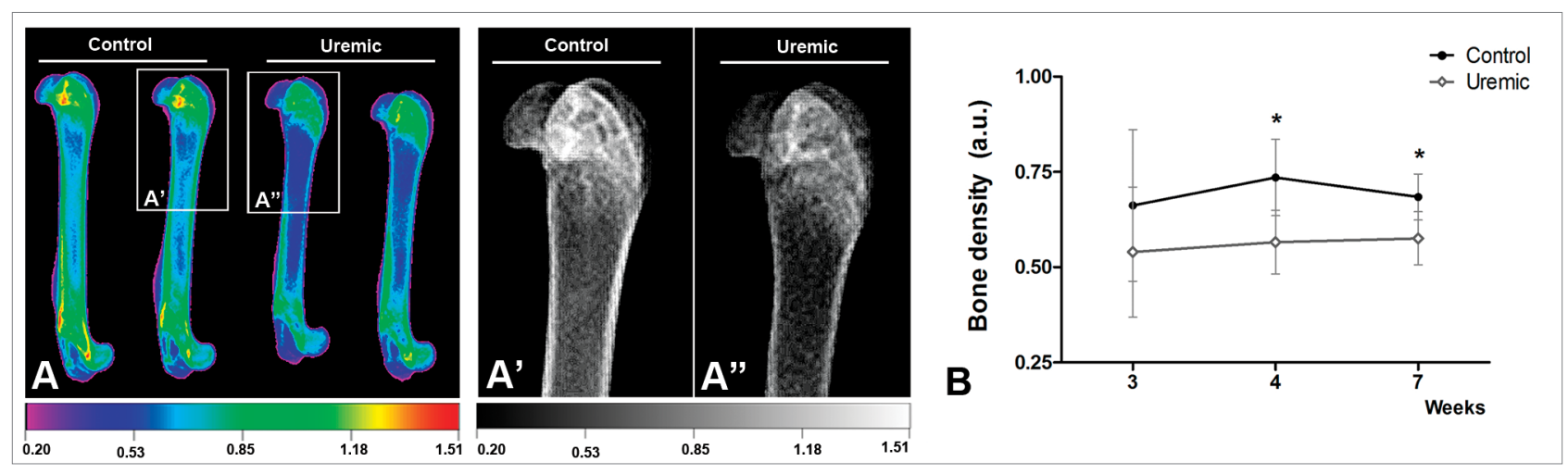

ASSOCIATION BETWEEN BD AND ASPECTS OF BONE HISTOMORPHOMETRY AND BIOCHEMICAL PARAMETERS AT WEEK 7

Results of Pearson's and Spearman's correlation analysis, evaluating the association between $\mathrm{BD}$, measured by DRx, and selected aspects of bone histomorphometry and selected biochemical parameters of MBD in CKD are shown in Figure 4. The analysis revealed a significant inverse correlation between $\mathrm{BD}$ and $\mathrm{P}(\mathrm{r}=-0.81 ; p=0.002)$ (Figure 4A), ALP $(\mathrm{r}=$ $-0.69, p=0.01)$ (Figure 4B), PTH $(\mathrm{r}=-0.83, p=0.01$ ) (Figure 4C), OS/BS ( $\mathrm{r}=-0.70 ; p=0.02)$ (Figure 4D), and Ob.S/BS ( $\mathrm{r}=-0.70 ; p=0.02$ ) (Figure 4E).

\section{Discussion}

CKD induces significant change in bone remodeling mechanisms, resulting in an imbalance between bone formation and reabsorption. The resulting changes in mineral organic content of bone can be measured by various methods ${ }^{5,18}$. To our knowledge, the application of DRx for analysis of BD in uremic experimental models has not been previously evaluated. Recently, the analysis of BD in patients with CKD has gained importance in clinical practice because of its association with increased risk for fractures, and increased overall and cardiovascular mortality ${ }^{19,20}$. 
Figure 4. Pearson's and Spearman's correlation between bone density measured by Digital Radiography (DRx) and biochemical parameters at week 7: (A) Correlation between bone densisty (BD) and Serum phosphate (P); (B) Correlation between BD and alkaline phosphatase (ALP); and (C) Correlation between BD and Parathyroid hormone (PTH); (D) Correlation between BD and Osteoid Surface/Bone Surface (OS/BS); (E) Correlation between BD and Osteoblast Surface/Bone Surface (Ob.S/BS)
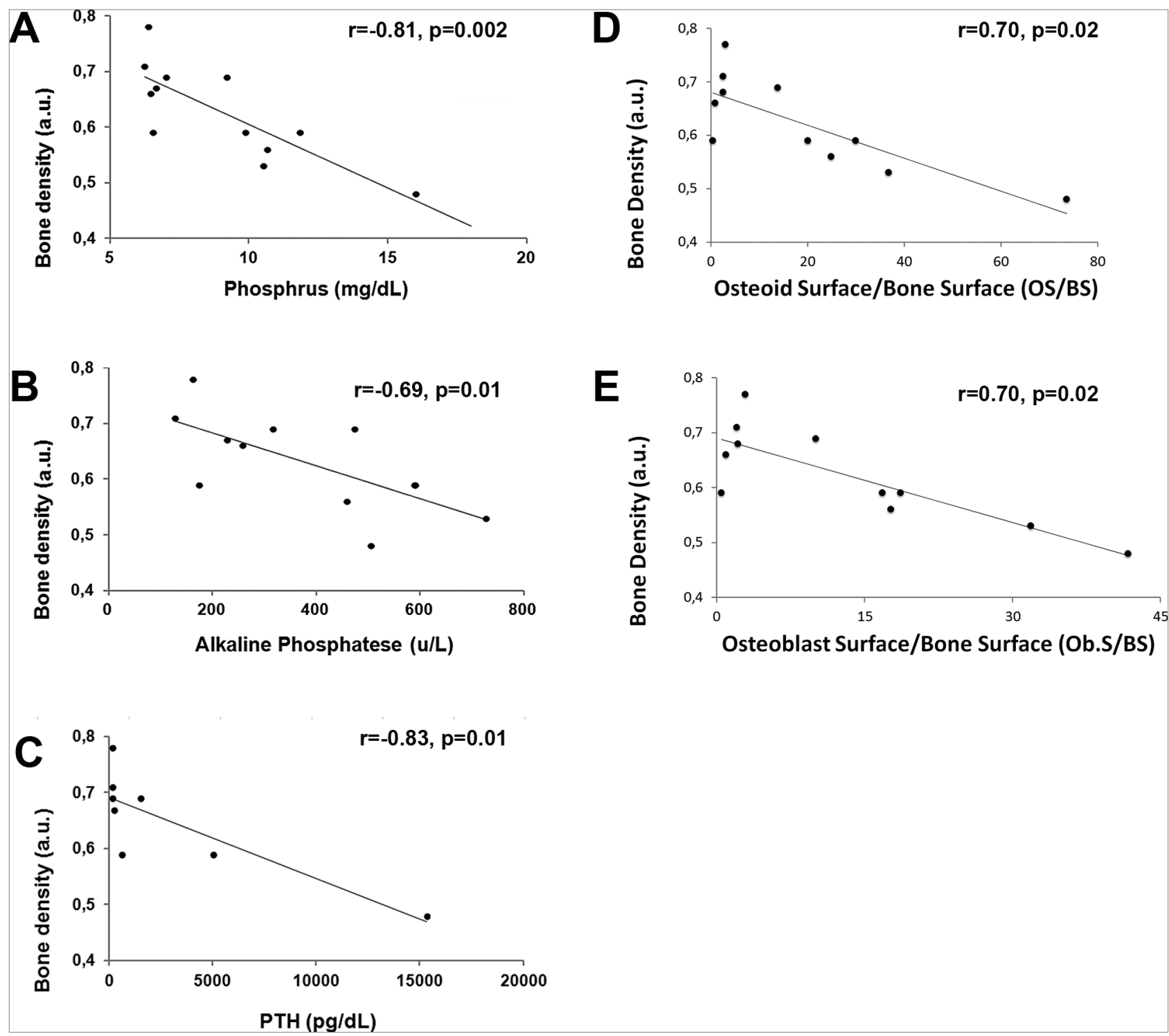

We adapted the adenine model as previously described $^{21}$. Damment et al. modified the original protocol of feeding animals with $0.75 \%$ adenine for 4 weeks, by adding a maintenance phase consisting of a $0.1 \%$ adenine diet for 18 weeks ${ }^{21}$. In our study, we used the initial 4 weeks of $0.75 \%$ adenine feeding and added 3 weeks of $0.1 \%$ adenine feeding. Our adapted adenine feeding protocol aimed to extend the period of renal dysfunction while reducing mortality ${ }^{21}$.

In our experimental model, glomerular filtration rate (GFR), estimated by $\mathrm{CrC}$, was reduced by $75 \%$ from normal values in the Uremic group at the end of the experiment. Extrapolating our data to The Kidney Disease: Global Improving Outcomes (KDIGO)

classification of CKD, we can infer that the GFR reduction in Uremic animals was equivalent to patients with category $4^{22}$.

MBD is common at this category of experimental $\mathrm{CKD}^{23}$. However, CKD MBD sings are present early in the course of CKD, with abnormal serum levels of P, Ca, FGF-23, PTH, and calcitriol, which precede identifiable changes in $\mathrm{BD}^{24}$. These early changes were demonstrated by Pereira et al., who reported increased FGF-23 production by osteocytes in patients with category $2 \mathrm{CKD}^{25}$. In the transition from category 2 to 3 , the reduction of GFR promotes a $P$ overload, which stimulates the secretion of FGF-23 and increases phosphaturia ${ }^{26,27}$. As CKD progresses, 
increased levels of FGF-23 reduce calcitriol levels and, consequently, increase levels of PTH in an attempt to maintain P homeostasis ${ }^{24,28}$. The biochemical changes, mainly hyperphosphatemia, are most evident when patients progress to category $4 \mathrm{CKD}^{29}$.

In addition to the reduction in $\mathrm{CrC}$, our data reproduced the kinetics of both early and late biochemical indicators of CKD MBD; early biochemical markers included a rise in FeP and FGF-23 levels, with elevation of PTH levels and hyperphosphatemia as late markers. In experimental models, these biochemical changes, and hyperphosphatemia more specifically, have been correlated to an increased prevalence of vascular calcification, bone disorders, and mortality $^{30-32}$. ALP is another biochemical marker of CKD that has traditionally been linked to bone remodeling and cardiovascular risk in uremic patients, also augmented as the renal function decreases ${ }^{33,34}$.

We believe that the absence of significant elevation of FGF 23 in our study was due to the large intra-group variation of uremic animals in the fourth week. In addition, we observed that serum calcium levels increased during CKD onset. A potential explanation could be the peculiar feature of the experimental model. Adenine can induce elevation of serum calcium, as described in other studies, because in addition to inducing $\mathrm{CKD}$, it acts directly on osteoblasts compromising their mineralization capacity, inducing a severe bone disease with high remodeling rate ${ }^{35-37}$.

Bone abnormalities in animal models have predominantly been associated to elevated levels of $\mathrm{PTH}^{36,38}$. In our model, PTH levels increased during the experiment, but levels were statistically different to the Control group only at the early time-points of measurement. The absence of between-group differences at later time-points likely reflects the large between-animal variability in PTH levels in $\mathrm{CKD}^{36}$.

Patients with CKD have a high prevalence of fractures when compared to the general population, which shows that renal dysfunction increases the risk for this condition ${ }^{19,20}$. After the 2012 KDIGO guidelines, the evaluation of $\mathrm{BD}$ has increasingly been included as a component of the clinical investigation of CKD patients, justified by the importance of early diagnosis of fracture risk and the need to evaluate new therapies aiming to preserve bone mass in this population'.

The risk of bone fracture is defined as a bone's capacity to maintain its structure under an applied force.
This capacity is directly related to $\mathrm{BD}$, bone quality, and bone remodeling rate ${ }^{39}$. $\mathrm{BD}$ is the fraction of bone than can be quantified. While commonly evaluated by DXA, BD has more recently been evaluated by QCT, which discriminates cortical and trabecular bone ${ }^{5,40}$. However, rapid and less expensive techniques, like DRx, can also be applied to assess trabecular bone mass and the more general features of disease-related changes in BD. DRx has the advantage of being easier to use than DXA and QCT and more feasible for basic research ${ }^{13}$, beeing increasingly used to provide surrogate measures of BD in small animals ${ }^{10,11,13,41,42}$. DRx imaging was reported to be comparable to other imaging techniques (DXA and QCT), biochemical markers, and histological patterns for differentiating normal and developing bone $\mathrm{e}^{10,13}$, as well as for identifying bone effects of various conditions including diabetes mellitus ${ }^{42}$, titanium implants ${ }^{41}$, disuse-induced bone $\operatorname{loss}^{11}$, and osteoporosis ${ }^{43}$. Studies on whole bone assessment of MBD in experimental models of CKD were not found in the literature. In our experiments, lower BD measured by DRx was found in uremic animals at all measurement time-points, and $\mathrm{BD}$ changes correlated to changes in biochemical markers of MBD featured by the elevation of PTH, P, and ALP and to changes of bone histomorphometry characteristic of a high-turnover bone disease. Therefore, there was a direct link between reduced BD and high-turnover bone disease found in $\mathrm{CKD}^{44}$. The absence of correlation between the trabecular volume and $\mathrm{BD}$ can be explained by the unique features of the adenine model. Adenine acts directly on osteoblasts compromising the cells capacity of mineralization and inducing a relative hypercalcemia and a high-turnover bone disease ${ }^{35-37}$. In our study, we found an increased osteoid surface evidencing compromised bone calcification; however, we also identified high bone reabsorption characterized by the increased osteoclast surface. Therefore, in the absence of bone tissue mineralization, $\mathrm{BD}$ measured by $\mathrm{Rx}$ is lower than that found in control animals.

The limitations of our study should be acknowledged. While previous studies in rodents have demonstrated a good correlation of DRx findings with DXA and QCT results, as well as with serum markers of bone disease, inclusion of another imaging technique for comparison would have strengthened the findings of our study ${ }^{10}$. 


\section{Conclusion}

In conclusion, DRx was able to detect $\mathrm{BD}$ reduction in femurs of uremic rats and results were associated with markers of CKD-related high-turnover bone disease. Thus, DRx is a helpful tool in the study of BD in animal models of CKD.

\section{Acknowledgments}

This work was supported by Rede Mineira de Bioterismo [grant number: 0009/14] and Rede Mineira de Ensaios Toxicológicos e Farmacológicos [grant number: 0008/14]. Bárbara Bruna Abreu de Castro is supported by the Fundação Instituto Mineiro de Estudos e Pesquisas em Nefrologia (IMEPEN), Coordenação de Aperfeiçoamento de Pessoal de Nível Superior (CAPES) and the Fundação de Apoio a Pesquisa do Estado de Minas Gerais (FAPEMIG).

\section{Authors' CONTRIBUTION}

Helady Sanders-Pinheiro designed the study and prepared the first draft of the paper. She is guarantor. Bárbara Bruna Abreu de Castro designed the study, prepared the first draft of the paper and did the experimental work and statistical analysis of the data. Wander Barros do Carmo designed the study, did the experimental work and statistical analysis of the data. Jasmin, Roberto Sotto-Maior Fortes Oliveira, Vera Maria Peters, Vanda Jorgetti, Melani Ribeiro Custodio contributed to the experimental work. All authors revised the paper critically for intellectual content and approved the final version. All authors agree to be accountable for the work and to ensure that any questions relating to the accuracy and integrity of the paper are investigated and properly resolved.

\section{Conflict of InTERest}

The authors declare that they have no conflict of interest related to the publication of this manuscript.

\section{References}

1. Clarke B. Normal bone anatomy and physiology. Clin J Am Soc Nephrol 2008;3:S131-9.

2. Popp AW, Meer S, Krieg MA, Perrelet R, Hans D, Lippuner K. Bone mineral density (BMD) and vertebral trabecular bone score (TBS) for the identification of elderly women at high risk for fracture: the SEMOF cohort study. Eur Spine J 2016;25:34328

3. Fitzpatrick LA. Secondary causes of osteoporosis. Mayo Clin Proc 2002;77:453-68.
4. Ibáñez R. Bone mineral density measurement techniques. An Sist Sanit Navar 2003;26:19-27.

5. Moorthi RN, Moe SM. Recent advances in the noninvasive diagnosis of renal osteodystrophy. Kidney Int 2013;84:886-94.

6. Bouxsein M. New advances in non-invasive evaluation bone resistance. Am Soc Bone Miner Res 2005;1:1-5.

7. Silva BC, Walker MD, Abraham A, Boutroy S, Zhang C, McMahon DJ, et al. Trabecular bone score is associated with volumetric bone density and microarchitecture as assessed by central QCT and HRpQCT in Chinese American and white women. J Clin Densitom 2013;16:554-61.

8. Ramalho J, Marques IDB, Hans D, Dempster D, Zhou H, Patel $\mathrm{P}$, et al. The trabecular bone score: Relationships with trabecular and cortical microarchitecture measured by HR-pQCT and histomorphometry in patients with chronic kidney disease. Bone 2018;116:215-20.

9. West SL, Lok CE, Langsetmo L, Cheung AM, Szabo E, Pearce $\mathrm{D}$, et al. Bone mineral density predicts fractures in chronic kidney disease. J Bone Miner Res 2015;30:913-9.

10. Bagi CM, Berryman E, Moalli MR. Comparative bone anatomy of commonly used laboratory animals: implications for drug discovery. Comp Med 2011;61:76-85.

11. Mabilleau G, Mieczkowska A, Libouban H, Simon Y, Audran $\mathrm{M}$, Chappard D. Comparison between quantitative X-ray imaging, dual energy X-ray absorptiometry and microCT in the assessment of bone mineral density in disuse-induced bone loss. J Musculoskelet Neuronal Interact 2015;15:42-52.

12. Syriopoulos K, Sanderink GC, Velders XL, van der Stelt PF. Radiographic detection of approximal caries: comparison of dental films and digital imaging systems. Dentomaxillofac Radiol 2000;29:312-8.

13. Jimenez-Mendoza D, Espinosa-Arbelaez DG, Giraldo-Betancur AL, Hernandez-Urbiola MI, Vargas-Vazquez D, Rodriguez-Garcia ME. Single x-ray transmission system for bone mineral density determination. Rev Sci Instrum 2011;82:125105.

14. Gouveia CH, Jorgetti V, Bianco AC. Effects of thyroid hormone administration and estrogen deficiency on bone mass of female rats. J Bone Miner Res 1997;12:2098-107. DOI: 10.1359/ jbmr.1997.12.12.2098

15. Moe S, Drüeke T, Cunningham J, Goodman W, Martin K, Olgaard $\mathrm{K}$, et al.; Kidney Disease: Improving Global Outcomes (KDIGO). Definition, evaluation, and classification of renal osteodystrophy: a position statement from Kidney Disease: Improving Global Outcomes (KDIGO). Kidney Int 2006;69:194553. DOI: $10.1038 /$ sj.ki.5000414

16. Dempster DW, Compston JE, Drezner MK, Glorieux FH, Kanis JA, Maluche H, et al. Standardized symbols, and units for bone histomorphometry: a 2012 update of the report of the ASBMR Histomorphometry Nomenclature Committee. J Bone Miner Res 2013;28:2-17. DOI: 10.1002/jbmr.1805

17. Jasmin, Jelicks LA, Tanowitz HB, Peters VM, Mendez-Otero R, de Carvalho ACC, et al. Molecular imaging, biodistribution and efficacy of mesenchymal bone marrow cell therapy in a mouse model of Chagas disease. Microbes Infect 2014;16:923-35.

18. Malluche HH, Davenport DL, Cantor T, Monier-Faugere MC. Bone mineral density and serum biochemical predictors of bone loss in patients with CKD on dialysis. Clin J Am Soc Nephrol 2014;9:1254-62.

19. Nickolas TL, Leonard MB, Shane E. Chronic kidney disease and bone fracture: a growing concern. Kidney Int 2008;74:72131.

20. Hirukawa T, Kakuta T, Nakamura M, Fukagawa M. Mineral and bone disorders in kidney transplant recipients: reversible, irreversible, and de novo abnormalities. Clin Exp Nephrol 2015;19:543-55

21. Damment SJ. Pharmacology of the phosphate binder, lanthanum carbonate. Ren Fail 2011;33:217-24.

22. Kidney Disease: Improving Global Outcomes (KDIGO) Chronic Kidney Disease Work Group. KDIGO 2012 clinical practice guideline for the evaluation and management of chronic kidney disease. Kidney Int Suppl 2013;3:1-150. 
23. Moe SM, Radcliffe JS, White KE, Gattone VH 2nd, Seifert MF, Chen X, et al. The pathophysiology of early-stage chronic kidney disease-mineral bone disorder (CKD-MBD) and response to phosphate binders in the rat. J Bone Miner Res 2011;26:267281.

24. Isakova T, Wahl P, Vargas GS, Gutiérrez OM, Scialla J, Xie H, et al. Fibroblast growth factor 23 is elevated before parathyroid hormone and phosphate in chronic kidney disease. Kidney Int 2011;79:1370-8.

25. Pereira RC, Juppner H, Azucena-Serrano CE, Yadin O, Salusky IB, Wesseling-Perry K. Patterns of FGF-23, DMP1 and MEPE expression in patients with chronic kidney disease. Bone 2009;45:1161-8.

26. Berndt T, Kumar R. Novel mechanisms in the regulation of phosphorus homeostasis. Physiology (Bethesda) 2009;24:1725.

27. Gutierrez O, Isakova T, Rhee E, Shah A, Holmes J, Collerone $\mathrm{G}$, et al. Fibroblast growth factor-23 mitigates hyperphosphatemia but accentuates calcitriol deficiency in chronic kidney disease. J Am Soc Nephrol 2005;16:2205-15.

28. Hamdy NA, Kanis JA, Beneton MN, Brown CB, Juttmann JR, Jordans JG, et al. Effect of alfacalcidol on natural course of renal bone disease in mild to moderate renal failure. BMJ 1995;310:358-63.

29. Levin A, Bakris GL, Molitch M, Smulders M, Tian J, Williams LA, et al. Prevalence of abnormal serum vitamin D, PTH, calcium, and phosphorus in patients with chronic kidney disease: results of the study to evaluate early kidney disease. Kidney Int 2007;71:31-8.

30. Lau WL, Linnes M, Chu EY, Foster BL, Bartley BA, Somerman MJ, et al. High phosphate feeding promotes mineral and bone abnormalities in mice with chronic kidney disease. Nephrol Dial Transplant 2013;28:62-9.

31. El-Abbadi MM, Pai AS, Leaf EM, Yang HY, Bartley BA, Quan $\mathrm{KK}$, et al. Phosphate feeding induces arterial medial calcification in uremic mice: role of serum phosphorus, fibroblast growth factor-23, and osteopontin. Kidney Int 2009;75:1297307.

32. Finch JL, Lee DH, Liapis H, Ritter C, Zhang S, Suarez E, et al. Phosphate restriction significantly reduces mortality in uremic rats with established vascular calcification. Kidney Int 2013;84:1145-53.
33. Kalantar-Zadeh K, Shah A, Duong U, Hechter RC, Dukkipati $\mathrm{R}$, Kovesdy CP. Kidney bone disease and mortality in CKD: revisiting the role of vitamin $\mathrm{D}$, calcimimetics, alkaline phosphatase, and minerals. Kidney Int Suppl 2010;117:10-21.

34. Taliercio JJ, Schold JD, Simon JF, Arrigain S, Tang A, Saab $\mathrm{G}$, et al. Prognostic importance of serum alkaline phosphatase in CKD stages 3-4 in a clinical population. Am J Kidney Dis 2013;62:703-10

35. Orriss IR, Burnstock G, Arnett TR. Purinergic signalling and bone remodelling. Curr Opin Pharmacol 2010;10:322-30.

36. Ferrari GO, Ferreira JC, Cavallari RT, Neves KR, dos Reis LM, Dominguez WV, et al. Mineral bone disorder in chronic kidney disease: head-to-head comparison of the 5/6 nephrectomy and adenine models. BMC Nephrol 2014;15:69.

37. Yaguchi A, Tatemichi S, Takeda H, Kobayashi M. PA21, a novel phosphate binder, improves renal osteodystrophy in rats with chronic renal failure. PLoS One 2017;12:e180430.

38. Meng Y, Zhang H, Li Y, Li Q, Zuo L. Effects of unfractionated heparin on renal osteodystrophy and vascular calcification in chronic kidney disease rats. Bone 2014;58:168-76.

39. Felsenberg D, Boonen S. The bone quality framework: determinants of bone strength and their interrelationships, and implications for osteoporosis management. Clin Ther 2005;27:1-11.

40. Hind $\mathrm{K}$, Oldroyd B, Truscott JG. In vivo precision of the GE Lunar iDXA densitometer for the measurement of total-body, lumbar spine, and femoral bone mineral density in adults. J Clin Densitom 2010;13:413-7.

41. Sakakura CE, Neto RS, Bellucci M, Wenzel A, Scaf G, Marcantonio E Jr. Influence of homeopathic treatment with comfrey on bone density around titanium implants: a digital subtraction radiography study in rats. Clin Oral Implants Res 2008;19:6248.

42. de Morais JA, Trindade-Suedam IK, Pepato MT, Marcantonio E Jr, Wenzel A, Scaf G. Effect of diabetes mellitus and insulin therapy on bone density around osseointegrated dental implants: a digital subtraction radiography study in rats. Clin Oral Implants Res 2009;20:796-801.

43. Beier EE, Maher JR, Sheu TJ, Cory-Slechta DA, Berger AJ, Zuscik MJ, et al. Heavy metal lead exposure, osteoporotic-like phenotype in an animal model, and depression of Wnt signaling. Environ Health Perspect 2013;121:97-104.

44. Rix M, Andreassen H, Eskildsen P, Langdahl B, Olgaard K. Bone mineral density and biochemical markers of bone turnover in patients with predialysis chronic renal failure. Kidney Int 1999;56:1084-93. 